Slavica

bruxellensia

\section{Slavica bruxellensia}

Revue polyphonique de littérature, culture et histoire

slaves

$1 \mid 2008$

Théâtre

\title{
Svetislav Basara, Perdu dans un supermarché
}

\section{Katia Vandenborre}

\section{OpenEdition \\ Journals}

Édition électronique

URL : http://journals.openedition.org/slavica/238

DOI : $10.4000 /$ slavica.238

ISSN : 2034-6395

Éditeur

Université libre de Bruxelles - ULB

Édition imprimée

Pagination : 69

ISSN : 2031-7654

Référence électronique

Katia Vandenborre, "Svetislav Basara, Perdu dans un supermarché », Slavica bruxellensia [En ligne], 1 | 2008, mis en ligne le 15 octobre 2008, consulté le 22 septembre 2020. URL : http:// journals.openedition.org/slavica/238; DOI : https://doi.org/10.4000/slavica.238

Ce document a été généré automatiquement le 22 septembre 2020.

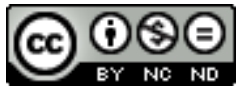

Les contenus de Slavica bruxellensia sont mis à disposition selon les termes de la Licence Creative Commons Attribution - Pas d'Utilisation Commerciale - Pas de Modification 3.0 France. 


\title{
Svetislav Basara, Perdu dans un supermarché
}

\author{
Katia Vandenborre
}

\section{RÉFÉRENCE}

Svetislav Basara, Perdu dans un supermarché, Montréal, Les allusifs, 2008, 178 p. Traduit du serbe par Gojko Lukič 
1 Tomber amoureux dans le jazz de la nature quand on est pris d'élancements dans le bras. Souffrir d'un incurable serpent dans le sein après que sa mère ait été enlevée par des esclavagistes. Se dégonfler à la brûlure de cigarette lors d'une boum fatale. Discuter avec Dieu par téléphone dans un supermarché. Telles sont les aventures plus loufoques les unes que les autres dont Svetislav Basara nous tisse le décousu dans Perdu dans un supermarché.

2 Ce recueil réunit une vingtaine de nouvelles liées, déliées voire délitées, dont la teneur absurde et insensée suit le fil d'une déconstruction en délire. Loin d'être innocente, la folie de cet écrivain, éditorialiste et diplomate qui se met en scène pousse le lecteur à s'interroger sur la condition humaine.

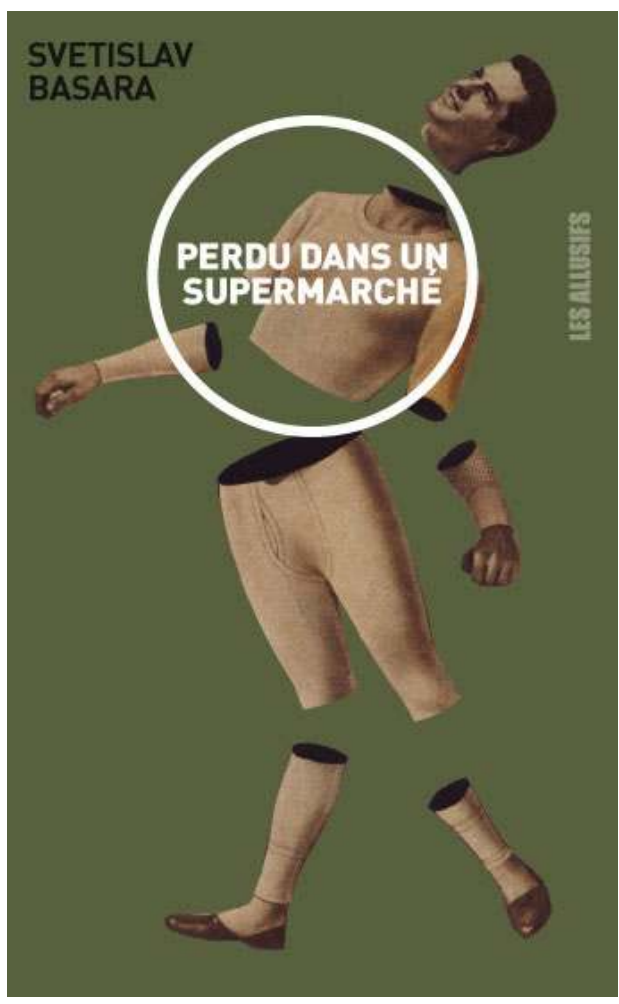

3 Sous la plume de Basara, cette réflexion de fond passe d'abord par une remise en question de la forme. Montés avec humour et sarcasme, les labyrinthes de mise en abyme, métatextualité et autofiction semblent faire perdre à ces nouvelles pseudoautobiographiques leur contenance, leur crédibilité, voire leur réalité.

4 Cette littérature circulaire, gorgée de points d'interrogation métaphysiques et existentiels, se confond chez Basara avec le chaos d'un monde sans issue. Mais expérimenter l'absurde ne nous permet-il pas d'échapper à la dictature du rationalisme?

\section{INDEX}

Mots-clés : littérature serbe

Index géographique : Serbie

\section{AUTEURS}

\section{KATIA VANDENBORRE}

Doctorante à l'Université Libre de Bruxelles (Belgique) et à l'Université de Varsovie (Pologne) ; membre du comité de rédaction de «Slavica Bruxellensia » 